\title{
An Analysis of COVID-19 Cases in G20 Countries and History of Previous Pandemics
}

\author{
Monika Garg, Nidhi Garg, Nishit Handa
}

\begin{abstract}
This research paper focusses on the recent impact of Covid-19 on the G20 countries on basis of the number of cases and the number of deaths in several aspects. This paper also provides a brief history of the previously occurred pandemics and epidemics. A statistical analysis was conducted for 19 countries of the G20 assembly and presented in the paper. This topic was chosen in interest of recent events of the Covid-19 pandemic and its extensive effect on the world at large. The dataset consisting of records from nineteen countries was chosen as a part of the analysis. Apart from being involved in the G20 summit, these countries are looked upon by other countries of the world due to their economic and overall development. Further, past history of some pandemics and epidemics were taken into study
\end{abstract}

Keywords. COVID-19, Pandemic, G20 countries, Analysis.

\section{I.INTRODUCTION}

\section{Covid-19 is caused by the novel Corona Virus which}

is a group of related viruses that causes infectious diseases in mammals and birds. In humans, these viruses can mostly lead to respiratory tract infections that can either be mild or fatal. As on $22^{\text {nd }}$ April, 2020 there have been 184,066 deaths worldwide due to this lethal virus. No vaccine had been made till date. The novel Corona Virus has spread throughout the world in a very brief amount of time. Both developed and developing countries took a major blow, thereby putting the entire world at lockdown. Although adopting this lockdown was the only and mandatory alternative for the countries to follow; their economies were highly affected. The Gross Domestic Product also known as the GDP of every country has suffered and is still suffering a major blow as all businesses in every country whether small or large, have completely shut down [1-4]. Out of the total 195 countries in the world present today, there is a group of twenty or G20 (19 countries and the European Union) which was solely formed with the aim to discuss policy pertaining to the promotion of international financial stability. So now with the chances of recession increasing dramatically worldwide we have to see what measures these countries take to stabilize the economy [5].

Manuscript received on 28 May 2021 | Revised Manuscript received on 06 October 2021 | Manuscript Accepted on 15 November 2021 | Manuscript published on 30 November 2021. * Correspondence Author and Engineering, Manav Rachna Indore, (Madhya Pradesh) India.

Nidhi Garg*, Assistant Professor, Department of Computer Science and Engineering, Manav Rachna Indore, (Madhya Pradesh) India.

Nishit Handa, Department of Computer Science Engineering Graduate from Manav Rachna Indore, (Madhya Pradesh) India.

(c) The Authors. Published by Lattice Science Publication (LSP). This is an open access article under the CC-BY-NC-ND license (http://creativecommons.org/licenses/by-nc-nd/4.0/)
Monika Garg, Assistant Professor, Department of Computer Science

This research paper mainly reviews how COVID-19 has affected these 19 countries and a review of how past epidemics and pandemics have affected the world population at large. The organization of this paper is as follows: Section 1 gives a brief introduction of COVID-19 pandemic. History of pandemics is presented in Section 2. Section 3 explains the research work carried out in the paper. Analysis is described in Section 4. Section 5 gives conclusions and Future scope followed by references

\section{II.HISTORY OF PANDEMICS}

The differences between Epidemics and Pandemics is as follows:An Epidemic is a form of disease that only affects a large number of people within a given group, population or area. Whereas a pandemic is an epidemic spreading across multiple countries or continents and affecting a large number of individuals.

Several well-heard viruses like the Ebola virus and the Zika virus are declared as epidemics with the African continent being their epicenter. The United States has also seen 11 number of cases of the Ebola virus including 2 deaths.

Ebola had checked the worldwide resilience of the health care systems. Back then, the disease had drawn particular attention to the inadequacies of the health care systems of sub-Saharan African countries, and the lack of health care infrastructure to deal with complex health emergencies in low-resource, developing country settings [6].

The SARS or Severe Acute Respiratory Syndrome outbreak in 2003 was also declared as an epidemic and not a pandemic. Although COVID-19 and SARS belong to the same family of the coronavirus, the former was declared a pandemic by WHO because of its widespread over several continents and countries.

The simple reproduction number $\mathrm{R} 0$ is specified as the number of secondary cases that should be created in a completely susceptible population from a single case. R0 is measured to explain how it can reflect the spread of these infectious diseases. It depends on the length of the infectious cycle, the probability that a susceptible person will be infected during one contact and the amount of new susceptible individuals contacted per unit of time. We have different values of the basic reproduction number for different infections / diseases but also for the same disease in different populations. A bar graph depicting R0 for various epidemics and pandemics is shown in Fig. 1.

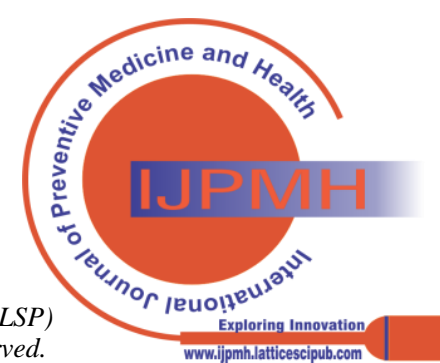




\section{An Analysis of COVID-19 Cases in G20 Countries and History of Previous Pandemics}

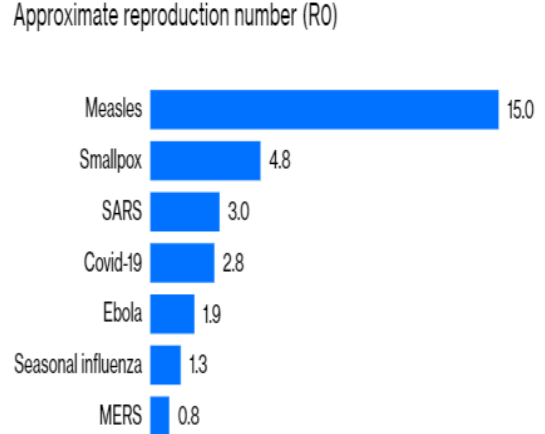

Sources: World Health Organization, Centers for Disease Control, King Saud University, Nature

Fig. 1. R0 for various epidemics and pandemics This section reviews the history of major pandemics that occurred on a large scale [7-10]. There have been a total of four pandemics in the span of last 130 years or so. Mainly these pandemics occurred in the years: 1889, 1918, 1957 and 1968. During 1889-1892, the world saw three extended waves of the H2N2 virus [11-12]. In May 1889, it began in Turkestan, then after several months reached Berlin and Paris. After a few weeks it crossed the ocean to the United States and then to Japan and Hong Kong. The second wave was mainly transferred by ships. Then in October 1891, the third wave began, making it a true pandemic. This wave was the most lethal one and it lasted until the spring of 1892. There are no reliable statistics available for this.

Then in January 1918, the first cases (Flu pandemic) emerged in the US and spread rapidly in their Army camps. It spread through Europe by April of the same year. It spread across the globe in the form of three waves, infecting over one third of the world's population and ending the lives of 20 to 50 million people [13-16].

The Asian flu originated in China in 1956 and lasted till 1958. It initially spread to Singapore, Hong Kong and then later on to the United States. WHO claims approximately 2 million deaths and 69,800 of those in the US itself [17-18]. In 1968, the H3N2 virus originated in Hong Kong and within 3 months it had spread to The Philippines, India, Australia, Europe and the United States. This pandemic had a low mortality rate of $0.5 \%$ but still resulted in the deaths of more than a million people [19-21].

Another global pandemic is the HIV/AIDS which has killed more than 36 million people since 1981. There are still roughly 31 to 35 million people living with HIV [22-23].

\section{III.RESEARCH WORK}

The Research approach followed in this paper is shown in Fig. 2. It consists of four steps. First of all, G20 countries were identified. Then, dataset related to COVID-19 was collected, consisting of parameters- Total cases, New cases, Total deaths, New deaths, Total cases per million, New cases per million, Total deaths per million and New deaths per million. As a third step, Statistical analysis was performed on dataset. Finally, graphs were plotted corresponding to the analysis performed. These steps are described as follows.

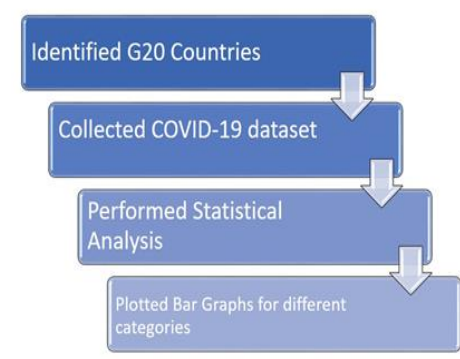

Fig. 2. Research Outline

\subsection{Identified G20 countries}

First of all, identification of G20 countries was done. G20 countries are- Argentina, Australia, Brazil, Canada, China, France, Germany, India, Indonesia, Italy, Japan, Mexico, Russia, Saudi Arabia, South Africa, South Korea, Turkey, United Kingdom, United States.

\subsection{Dataset Collection}

Dataset on COVID-19 was collected [24], consisting of several parameters- Total cases, New cases, Total deaths, New deaths, Total cases per million, New cases per million, Total deaths per million and New deaths per million.

\subsection{Statistical Analysis and Graphs Plotted}

Analysis was performed on the collected dataset and accordingly graphs were plotted. Details given in Section 4.

\section{ANALYSIS}

Analysis has been performed on the data in three perspectives:

- Total Cases and Total Deaths per Country

- Total Cases per million and Total Deaths per million

- New Cases per million and New Deaths per million

\subsection{Total Cases and Total Deaths per Country}

The graph plotted after analysing total cases and total deaths per country is shown in Fig. 3. It can be seen that among the given countries, United States is at the peak with the most number of cases $(825,041)$ and deaths $(45,063)$ followed by Italy with the second highest number of cases and deaths recorded. As a matter of fact, The United States itself contributes $45.87 \%$ to the total number of cases for the 19 countries combined.

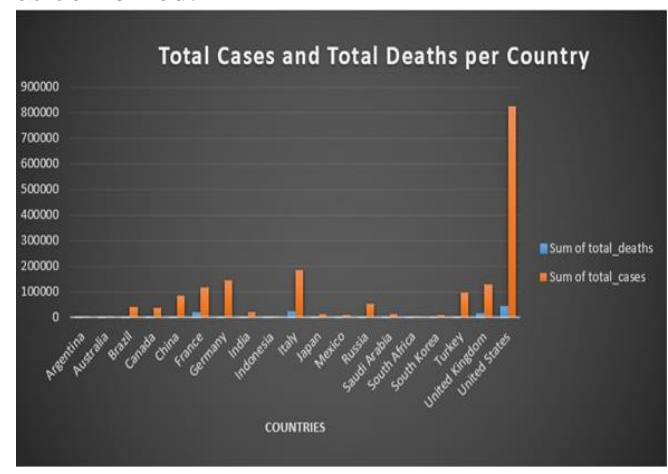

Fig. 3. Total cases and total deaths in G20 countries

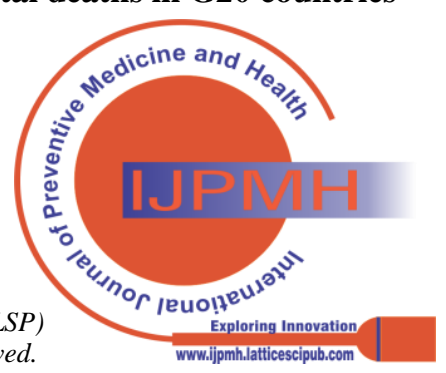


4.2 Total Cases per million and Total Deaths per million The graph plotted after analysing total cases per million and total deaths per million is shown in Fig. 4.In this graph we see a rise in the bars of Italy, making Italy the most affected country in respect to the cases occurring per million. Following Italy, is The United States having second highest numbers. A surge can also be seen in small countries like Germany, United Kingdom, Turkey and France. These small countries tend to have smaller populations and hence the result.

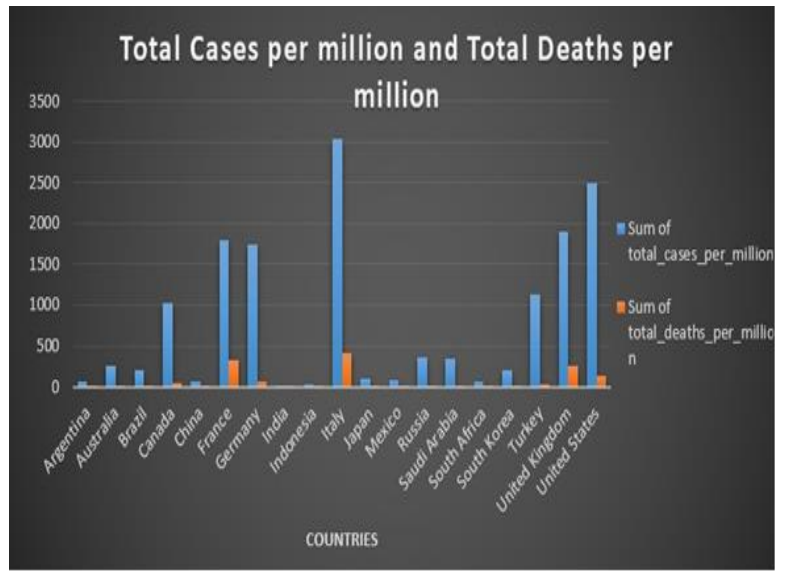

Fig. 4. Total cases and total deaths per million in G20 countries

4.3 New Cases per million and New Deaths per million

Fig. 5 shows the graph plotted after analysing New cases and new deaths per million. Analysis shows that although Italy leads in the category of total number of cases per million, it doesn't show the similar type of trend for the new cases per million. The United States has the most number of new cases per million and the United Kingdom has the most number of new deaths recorded. Also it can be seen that there is a significant rise in the number of cases for countries like Canada, France, Germany, Russia, Saudi Arabia and Turkey. Most of these countries which are a part of Europe, it can be concluded that the spread of corona virus is still spreading in large numbers in the same continent.

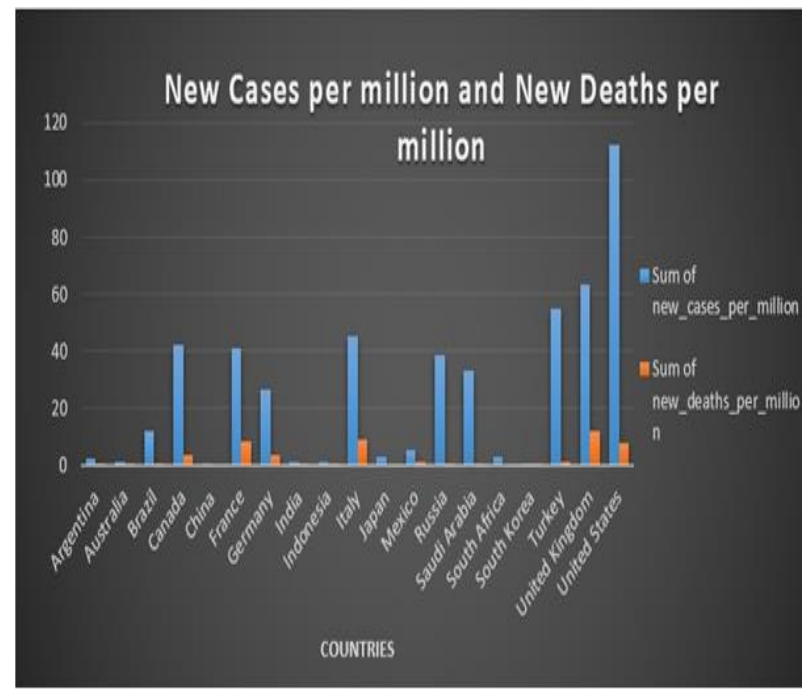

Fig. 5. New cases and new deaths per million in G20 countries

\section{V.CONCLUSIONS AND FUTURE SCOPE}

Following are the conclusions that can be made based on the research work done.Firstly, The United States have the most number of covid-19 cases among the other G20 countries. We still observe that the number of cases are rapidly increasing in the same country till date. Now this solely can be concluded from the fact that the need of a total shutdown of the country was neglected and hence the rise in number of cases. Secondly, for every country having small or medium population we tend to see a rise in the total number of cases per million, also given the fact that the country is seriously affected by the infection/disease. After observing the histories of several pandemics and epidemics, we see that the United States was affected in each one of the previous outbreaks. This is possible mainly because of the vast connections of the US with several other countries. Covid19 has a higher reproduction number R0 as compared to epidemics and pandemics like Ebola, MERS and the seasonal influenza. It is a mere prediction that covid-19 may surpass the reproduction number for SARS coronavirus as the former is turning out to be more lethal to the world population.

As future work, more recently updated data can be collected and analysis can be performed. Secondly several Machine Learning algorithms can be applied to predict the number of cases and deaths in future in different countries across the world, that will help medical experts to visualize the threat of COVID-19 in future and governments to make safety policies.

\section{REFERENCES}

1. The Global Economic Impact of COVID-19: A Summary of Research; Samuel Neaman Institute of National Policy Research; Prof. Shlomo \& Maital Ella Barzani; March 2020

2. A Remuzzi, G Remuzzi; COVID-19 and Italy: what next? Lancet (2020); March 2020 [CrossRef]

3. DS Jones; History in a crisis-lessons for Covid-19; N Eng J Med (2020); March 2020. [CrossRef]

4. Z Wu, JM McCoogan; Characteristics of and important lessons from the coronavirus disease 2019 (COVID-19) outbreak in China; JAMA (2020); Feb 2020.

5. Qiao, H., Zheng, F., Jiang, H., \& Dong, K. (2019). The greenhouse effect of the agriculture-economic growth-renewable energy nexus: evidence from G20 countries. Science of the Total Environment, 671, 722-731. [CrossRef]

6. Aaron G. Buseh, Patricia E. Stevens, Mel Bromberg, Sheryl T. Kelber; The Ebola epidemic in West Africa: Challenges, opportunities, and policy priority areas; Nursing Outlook, December 2014. [CrossRef]

7. Huremović, D. (2019). Brief history of pandemics (pandemics throughout history). In Psychiatry of pandemics (pp. 7-35). Springer, Cham. [CrossRef]

8. Gössling, S., Scott, D., \& Hall, C. M. (2020). Pandemics, tourism and global change: a rapid assessment of COVID-19. Journal of Sustainable Tourism, 29(1), 1-20. [CrossRef]

9. LePan, N. (2020). Visualizing the history of pandemics. Visual Capitalist, 14

10. Morganstein, J. C., Fullerton, C. S., Ursano, R. J., Donato, D., \& Holloway, H. C. (2017). Pandemics: health care emergencies. Textbook of disaster psychiatry, 270-284. [CrossRef]

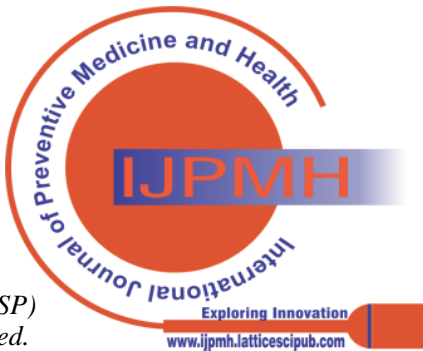




\section{An Analysis of COVID-19 Cases in G20 Countries and History of Previous Pandemics}

11. Scholtissek, C., Rohde, W. V., Von Hoyningen, V., \& Rott, R. (1978). On the origin of the human influenza virus subtypes H2N2 and H3N2. Virology, 87(1), 13-20. [CrossRef]

12. Lindstrom, S. E., Cox, N. J., \& Klimov, A. (2004). Genetic analysis of human H2N2 and early H3N2 influenza viruses, 1957-1972: evidence for genetic divergence and multiple reassortment events. Virology, 328(1), 101-119. [CrossRef]

13. Bloom, E., De Wit, V., \& Carangal-San Jose, M. J. (2005). Potential economic impact of an avian flu pandemic on Asia.

14. Pettit, D. A., \& Bailie, J. (2008). A Cruel Wind: Pandemic Flu in America, 1918-1920. Timberlane Books.

15. Johnson, N. P., \& Mueller, J. (2002). Updating the accounts: global mortality of the 1918-1920" Spanish" influenza pandemic. Bulletin of the History of Medicine, 105-115. [CrossRef]

16. Kolata, G. (2001). Flu: the story of the great influenza pandemic of 1918 and the search for the virus that caused it. Simon and Schuster.

17. Jackson, C. (2009). History lessons: the Asian Flu pandemic. British journal of general practice, 59(565), 622-623. [CrossRef]

18. Kelly, E. (2011). The scourge of asian flu in utero exposure to pandemic influenza and the development of a cohort of british children. Journal of Human resources, 46(4), 669-694. [CrossRef]

19. Kawaoka, Y., Krauss, S., \& Webster, R. G. (1989). Avian-to-human transmission of the PB1 gene of influenza A viruses in the 1957 and 1968 pandemics. Journal of virology, 63(11), 4603-4608. [CrossRef]

20. Jester, B. J., Uyeki, T. M., \& Jernigan, D. B. (2020). Fifty years of influenza A (H3N2) following the pandemic of 1968. American journal of public health, 110(5), 669-676. [CrossRef]

21. Westgeest, K. B., Russell, C. A., Lin, X., Spronken, M. I., Bestebroer, T. M., Bahl, J., ... \& de Graaf, M. (2014). Genomewide analysis of reassortment and evolution of human influenza A (H3N2) viruses circulating between 1968 and 2011. Journal of virology, 88(5), 28442857. [CrossRef]

22. Brodie, M., Hamel, E., Brady, L. A., Kates, J., \& Altman, D. E. (2004). AIDS at 21: Media coverage of the HIV epidemic 19812002. the nation, $49,68$.

23. 23.Centers for Disease Control and Prevention (CDC. (2006) Twenty-five years of HIV/AIDS--United States, 1981-2006. MMWR. Morbidity and mortality weekly report, 55(21), 585-589.

24. https://ourworldindata.org/coronavirus-source-data

\section{AUTHOR PROFILES}

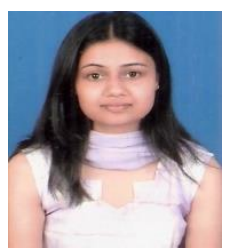

Monika Garg Specializes in the field of Data Mining and Machine Learning. Working as an Assistant Professor in the department of Computer Science and Engineering, Manav Rachna International Institute of Research and Studies. She has several research articles published in renowned journals and indexed in reputed databases- SCIE and Scopus.

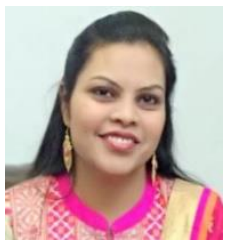

Nidhi Garg Specializes in the field of Machine Learning and Algorithms. Working as an Assistant Professor in the department of Computer Science and Engineering, Manav Rachna International Institute of Research and Studies. She has several research articles published in renowned journals and indexed in reputed databases- Web of Science and Scopus.

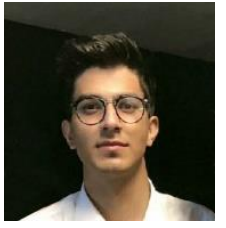

Nishit Handa A Computer Science engineering graduate from Manav Rachna International Institute of Research and Studies with specialization in Business Analytics and Optimization. He is a Data Science enthusiast who has worked on several projects in the same domain and continues to do so.

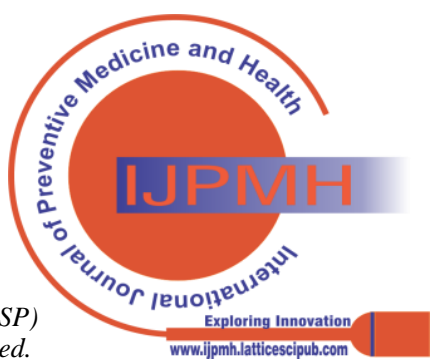

